\title{
THỰC TRẠNG STRESS VÀ MỌT SỐ YÊU TÓ LIÊN QUAN Ở SINH VIÊN RĂNG HÀM MẠT TRƯỜNG ĐẠI HỌC Y HÀ NỘI
}

\author{
Nguyễn Việt Anh ${ }^{1, 凶}$, Võ Trương Như Ngọc ${ }^{1}$, Chu Đình Tớ'i ${ }^{2}$ \\ ${ }^{1}$ Trường Đại học Y Hà Nội \\ ${ }^{2} Đ a ̣ i$ học Quốc gia Hà Nội
}

Stress là vấn đề ngày càng phổ biến, đặc biệt ở sinh viên. Stress có thể gây ảnh hưởng tiêu cực đến sức khỏe tâm thần, khả năng học tập, chất lượng cuộc sống của các bạn sinh viên. Sinh viên răng hàm mặt là nhóm đối tượng có nguy cơ cao bị stress do đó chúng tôi tiến hành nghiên cứu này nhằm mục tiêu mô tả thực trạng stress và một số yếu tố liên quan ở sinh viên răng hàm mặt đang học tập tại Trường Đại học $Y$ Hà Nội năm 2020-2021. Nghiên cứu được thực hiện theo phương pháp mô tả cắt ngang trên 383 sinh viên răng hàm mặt. Trong tổng số 383 sinh viên, có 256 sinh viên có stress (chiếm tỷ lệ 66,84\%), tỷ lệ stress ở nam là 63,45\%; ở nữ là 68,91\%. Theo mức độ stress, tỷ lệ sinh viên bị stress ở mức độ trung bình chiếm tỷ lệ cao nhất $34,46 \%$, mức độ nặng và rất nặng lần lượt là $8,88 \%$ và $6,27 \%$. Tỷ lệ stress theo năm học, cao nhất ở sinh viên năm thứ 6 là 73,97\%. Một số yếu tố liên quan đến tình trạng stress ở sinh viên răng hàm mặt bao gồm: thiếu tự tin vào bản thân, sụ̣ kỳ vọng của bố mẹ khiến cảm thấy áp lực. Như vậy, tỷ lệ stress ở sinh viên răng hàm mặt rất cao và liên quan đến sự tự tin của bản thân, áp lực từ kỳ vọng của bố mẹ.

Từ khóa: stress, sinh viên răng hàm mặt, thiếu tụ̣ tin, áp lực từ kỳ vọng của bố mẹ.

\section{I. ĐẠT VẤN ĐẺ}

Ngày nay, cùng với sự phát triển của xã hội, áp lực cuộc sống ngày càng tăng, stress trở thành vấn đề ngày càng phổ biến. Sinh viên ngành y nói chung và sinh viên răng hàm mặt nói riêng là nhóm đối tượng nhạy cảm, có nguy cơ stress rất cao do những khó khăn trong cuộc sống và trong học tập. ${ }^{1}$ Sinh viên răng hàm mặt phải học tập, ghi nhớ nhiều kiến thức lý thuyết và luyện tập các kỹ năng tiền lâm sàng, lâm sàng ngay từ những năm học đầu tiên. Bên cạnh đó áp lực kinh tế, áp lực thi cử, thời gian học cả ngày ở trường, phải trực đêm tại bệnh viện... khiến sinh viên răng hàm mặt dễ bị stress. ${ }^{2}$

Theo Tedesco và một số tác giả, stress gây ra các ảnh hưởng tiêu cực đến quá trình học tập của sinh viên răng hàm mặt và có thể dẫn

Tác giả liên hệ: Nguyễn Việt Anh

Trường Đại học Y Hà Nội

Email: vietanh.bsrhm@gmail.com

Ngày nhận: 27/04/2021

Ngày được chấp nhận: 16/05/2021 tới các vấn đề sức khỏe tâm thần khác như lo âu, trầm cảm... ${ }^{3,4}$ Trên thế giới, đã có nhiều tác giả nghiên cứu về thực trạng stress và các yếu tố liên quan đến stress ở sinh viên nha khoa

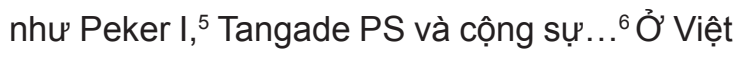
Nam, hiện chưa có nghiên cứu về stress ở đối tượng sinh viên răng hàm mặt, do đó chúng tôi tiến hành nghiên cứu này với mục đích: mô tả thực trạng stress và một số yếu tố liên quan ở sinh viên răng hàm mặt trường Đại học $Y$ Hà Nội năm 2020 - 2021.

\section{II. ĐÓI TƯƠ'NG VÀ PHƯƠNG PHÁP}

\section{1. Đối tượng}

Đối tượng nghiên cứu là các sinh viên Răng Hàm Mặt đang học tập tại Viện Đào tạo Răng Hàm Mặt - Trường Đại học $Y$ Hà Nội. Nghiên cứu được tiến hành từ tháng 03 năm 2020 đến tháng 03 năm 2021.

Tiêu chuẩn lựa chọn: sinh viên Răng Hàm Mặt đang học tập tại Viện Đào tạo Răng Hàm 
Mặt - Trường Đại học Y Hà Nội, đồng ý tự nguyện tham gia nghiên cứu và trả lời đầy đủ các câu hỏi trong bộ câu hỏi phỏng vấn.

Tiêu chuẩn loại trừ: sinh viên có chẩn đoán hoặc có tiền sử bị rối loạn sức khỏe tâm thần, có các dấu hiệu của tổn thương về tinh thần và nhận thức ảnh hưởng đến việc trả lời bộ câu hỏi trong nghiên cứu.

\section{Phương pháp}

Nghiên cứu được thực hiện theo phương pháp mô tả cắt ngang.

Cỡ mẫu: áp dụng công thức tính cỡ mẫu cho việc xác định một tỉ lệ trong cộng đồng trong nghiên cứu mô tả cắt ngang.

$$
\mathrm{n}=\mathrm{Z}_{(1-\alpha / 2)}^{2} \frac{\mathrm{p} .(1-\mathrm{p})}{\Delta^{2}}
$$

Trong đó:

n là cỡ mẫu tối thiểu.

$p=0,63$ là tỷ lệ sinh viên bị stress tại trường Đại học $Y$ Hà Nội theo nghiên cứu Phạm Thị Huyền Trang năm 2013. ${ }^{7}$

$\alpha$ là mức ý nghĩa thống kê, chọn $\alpha=0,05$, tra bảng $Z=1,96$.

$\Delta$ là sai số ngẫu nhiên của ước lượng, ở đây chọn $\Delta=0,05$.

Từ đó tính được $n=358,2$. Vậy cỡ mẫu tối thiểu cần 359 sinh viên. Thực tế chúng tôi tiến hành nghiên cứu được 383 sinh viên.

Chọn mẫu: chọn mẫu có chủ đích, lựa chọn sinh viên đang học tại Viện Đào tạo Răng hàm mặt, trường Đại học $Y$ Hà Nội thoả mãn tiêu chuẩn lựa chọn và không có yếu tố nào thuộc tiêu chuẩn loại trừ cho đến khi đủ cỡ mẫu nghiên cứu.
Các bước tiến hành nghiên cứu:

(1) Thiết kế phiếu điều tra,

(2) Tập huấn điều tra viên,

(3) Liên hệ thời gian và địa điểm thu thập số liệu,

(4) Lựa chọn đối tượng nghiên cứu theo tiêu chuẩn lựa chọn,

(5) Điều tra viên thu thập số liệu theo phiếu điều tra,

(6) Kiểm tra, nhập và xử lý số liệu,

(7) Viết báo cáo.

Bộ câu hỏi trong nghiên cứu sử dụng thang đo DASS 21 để đánh giá tỷ lệ và mức độ stress. Thang đo DASS 21 đã được Viện Sức khỏe Tâm thần Quốc gia biên dịch, thử nghiệm trên một số đối tượng nghề nghiệp khác nhau. Thang đo DASS 21 đã được một số nghiên cứu đánh giá về tính giá trị và độ tin cậy và khẳng định có thể thể áp dụng tại Việt Nam, không có sự khác biệt về mặt văn hóa. ${ }^{8}$

\section{Xử lý số liệu}

Số liệu được nhập và quản lý bằng phần mềm Excel 2010 và được phân tích bằng phần mềm SPSS 20.0.

\section{4. Đạo đức nghiên cứu}

Nghiên cứu đã thông qua hội đồng đạo đức nghiên cứu $Y$ sinh học - Trường đại học $Y$ Hà Nội, mã số 213/GCN-HĐĐĐNCYSH-ĐHYHN ngày 03 tháng 03 năm 2021.

\section{III.KÉT QUẢ}

\section{1. Đặc điểm của đối tượng nghiên cứu}

Bảng 1. Một số đặc điểm của đối tượng nghiên cứu

\begin{tabular}{|c|c|c|}
\hline & $\mathbf{N}$ & $\%$ \\
\hline Tuổi trung bình & \multicolumn{2}{|c|}{$20,47 \pm 1,92$} \\
\hline
\end{tabular}




\begin{tabular}{|c|c|c|c|}
\hline & & $\mathbf{N}$ & $\%$ \\
\hline \multirow{2}{*}{ Giới tính } & Nam & 145 & 37,86 \\
\hline & Nữ & 238 & 62,14 \\
\hline \multirow{4}{*}{ Tình trạng hôn nhân } & Chưa kết hôn & 376 & 98,17 \\
\hline & Có vợ/chồng & 4 & 1,04 \\
\hline & Ly thân/ly hôn & 1 & 0,26 \\
\hline & Góa bụa & 2 & 0,52 \\
\hline \multirow{6}{*}{ Sinh viên năm } & Năm thứ nhất & 77 & 20,1 \\
\hline & Năm thứ hai & 78 & 20,37 \\
\hline & Năm thứ ba & 55 & 14,36 \\
\hline & Năm thứ tư & 61 & 15,93 \\
\hline & Năm thứ năm & 39 & 10,18 \\
\hline & Năm thứ sáu & 73 & 19,06 \\
\hline \multirow{3}{*}{ Lý do thi vào khoa Răng Hàm Mặt } & Nguyện vọng bản thân & 262 & 68,41 \\
\hline & Bố mẹ lựa chọn & 38 & 9,92 \\
\hline & Khác & 83 & 21,67 \\
\hline
\end{tabular}

Nghiên cứu được thực hiện trên 383 sinh viên, trong đó có 145 sinh viên nam (chiếm tỷ lệ $37,86 \%$ ) và 238 sinh viên nữ (chiếm tỷ lệ 62,14\%). Tuổi trung bình của đối tượng nghiên cứu là 20,47 tuổi (bảng 1).

\section{Thực trạng stress ở sinh viên Răng Hàm Mặt}

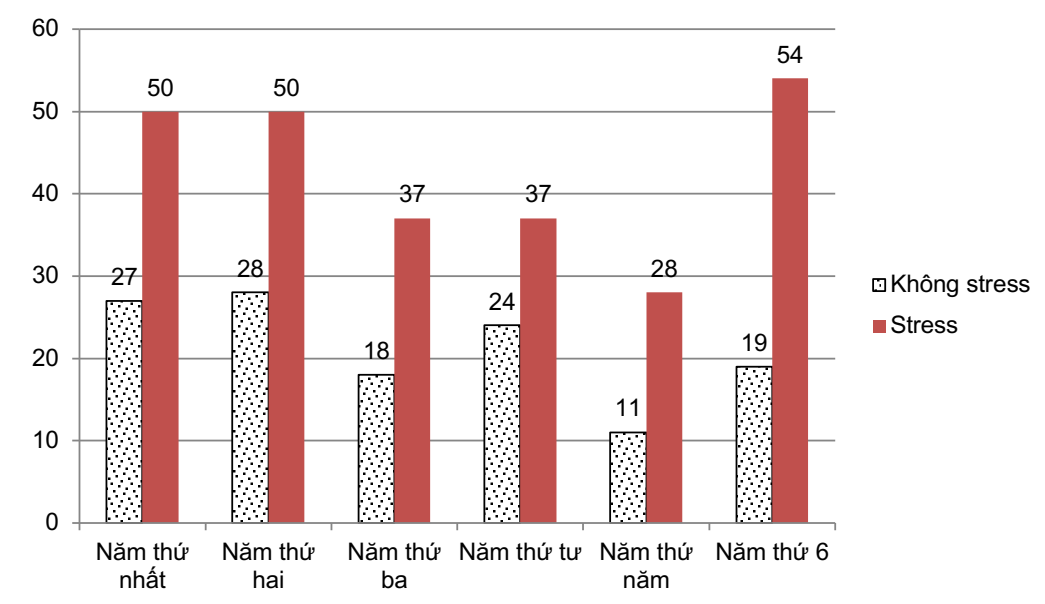

Biểu đồ 1. Thực trạng stress ở sinh viên Răng Hàm Mặt theo năm học.

Tỷ lệ sinh viên Răng Hàm Mặt có stress là 66,84\%, tỷ lệ sinh viên Răng Hàm Mặt không bị stress là $33,16 \%$. 
Theo giới tính, tỷ lệ stress ở sinh viên nam là 63,45\%, ở sinh viên nữ cao hơn với $68,91 \%$, tuy nhiên sự khác biệt này không có ý nghĩa thống kế ( $p>0,05)$.

Theo năm học, tỷ lệ stress cao nhất ở sinh viên năm thứ $6(73,97 \%)$, tiếp theo là sinh viên năm thứ 5 (71,79\%), tỷ lệ stress thấp nhất ở sinh viên năm thứ 4 với $60,66 \%$.

Về mức độ stress, sinh viên có mức độ stress trung bình chiếm tỷ lệ cao nhất $(34,46 \%)$, sinh viên bị stress mức độ nặng và rất nặng cũng chiếm tỷ lệ khá cao lần lượt là 8,88\% và $6,27 \%$.

3. Một số yếu tố liên quan đến stress ở sinh viên Răng Hàm Mặt

Bảng 2. Một số yếu tố liên quan đến stress ở sinh viên Răng Hàm Mặt (phân tích đơn biến)

\begin{tabular}{|c|c|c|c|c|}
\hline \multirow{2}{*}{ Nội dung } & \multicolumn{2}{|c|}{ Stress } & \multirow{2}{*}{ OR $(95 \% \mathrm{Cl})$} & \multirow{2}{*}{$\mathbf{P}$} \\
\hline & Có (\%) & Không (\%) & & \\
\hline \multicolumn{5}{|c|}{ 1. Điều kiện sống } \\
\hline \multicolumn{5}{|c|}{ Vấn đề tại nơi ở ảnh hưởng đến sinh hoạt hàng ngày } \\
\hline Không & 58,98 & 70,87 & \multirow{2}{*}{$1,69(1,07-2,67)$} & \multirow{2}{*}{0,024} \\
\hline Có & 41,02 & 29,13 & & \\
\hline \multicolumn{5}{|c|}{ Môi trường sống tại nơi ở ảnh hưởng đến học tập } \\
\hline Không & 55,86 & 73,23 & \multirow{2}{*}{$2,16(1,35-3,43)$} & \multirow{2}{*}{0,001} \\
\hline Có & 44,14 & 26,77 & & \\
\hline \multicolumn{5}{|c|}{ 2. Yếu tố cá nhân } \\
\hline \multicolumn{5}{|c|}{ Khó khăn về tài chính } \\
\hline Không & 48,44 & 64,57 & \multirow{2}{*}{$1,93(1,25-3,00)$} & \multirow{2}{*}{0,003} \\
\hline Có & 51,56 & 35,43 & & \\
\hline \multicolumn{5}{|c|}{ Thiếu thời gian nghỉ ngơi } \\
\hline Không & 61,42 & 46,88 & \multirow{2}{*}{$1,80(1,16-2,78)$} & \multirow{2}{*}{0,008} \\
\hline Có & 38,58 & 53,13 & & \\
\hline \multicolumn{5}{|c|}{ Thiếu thời gian cho các quan hệ xã hội } \\
\hline Không & 54,3 & 74,02 & \multirow{2}{*}{$2,39(1,50-3,82)$} & \multirow{2}{*}{0,000} \\
\hline Có & 45,7 & 25,98 & & \\
\hline \multicolumn{5}{|c|}{ Thiếu tự tin vào bản thân } \\
\hline Không & 28,52 & 59,06 & \multirow{2}{*}{$3,61(2,31-5,64)$} & \multirow{2}{*}{0,000} \\
\hline Có & 71,48 & 40,94 & & \\
\hline
\end{tabular}




\begin{tabular}{|c|c|c|c|c|}
\hline \multirow{2}{*}{ Nội dung } & \multicolumn{2}{|c|}{ Stress } & \multirow{2}{*}{ OR $(95 \% \mathrm{Cl})$} & \multirow{2}{*}{$\mathbf{P}$} \\
\hline & Có (\%) & Không (\%) & & \\
\hline Không & 82,81 & 95,28 & \multirow{2}{*}{$4,18(1,73-10,10)$} & \multirow{2}{*}{0,001} \\
\hline Có & 17,19 & 4,72 & & \\
\hline \multicolumn{5}{|c|}{ Thường xuyên luyện tập thể dục, thể thao } \\
\hline Không & 43,36 & 275,6 & \multirow{2}{*}{$0,49(0,31-0,78)$} & \multirow{2}{*}{0,003} \\
\hline Có & 56,64 & 72,44 & & \\
\hline \multicolumn{5}{|c|}{ Trong 01 năm có mất người thân } \\
\hline Không & 92,97 & 98,43 & \multirow{2}{*}{$4,72(1.07-20.69)$} & \multirow{2}{*}{0,039} \\
\hline Có & 7,03 & 1,57 & & \\
\hline \multicolumn{5}{|c|}{ Trong 01 năm có mất tài sản có giá trị } \\
\hline Không & 78,91 & 96,85 & \multirow{2}{*}{$6,67(2,60-17,13)$} & \multirow{2}{*}{0,000} \\
\hline Có & 21,09 & 3,15 & & \\
\hline
\end{tabular}

Tự đánh giá tình trạng sức khỏe của bản thân

\begin{tabular}{ccccc}
\hline Không khỏe \& rất yếu & 30,47 & 8,02 & $0,27(0,15-0,51)$ & 0,000
\end{tabular}

Sự kỳ vọng của bố mẹ khiến cảm thấy áp lực

\begin{tabular}{ccccc}
\hline Không & 42,19 & 68,5 & $2,98(1,90-4,67)$ & 0,001 \\
\cline { 1 - 2 } Có & 57,81 & 31,5 & \\
\hline
\end{tabular}

Lo lắng mình không trở thành 1 bác sỹ giỏi

\begin{tabular}{ccccc}
\hline Không & 12,11 & 25,2 & $2,44(1,41-4,23)$ & 0,001 \\
\cline { 1 - 2 } Có & 87,89 & 74,8 & \\
\hline
\end{tabular}

3. Yếu tố trường học

Dễ dàng tiếp cận, trao đổi với các giảng viên

\begin{tabular}{cllll}
\hline Không & 51,95 & 40,94 & $0,64(0,41-0,89)$ & 0,043 \\
\hline Có & 48,05 & 59,06 & & \\
\hline
\end{tabular}

Không khí học tập gây vấn đề tâm lý, sức khỏe

\begin{tabular}{cllll}
\hline Không & 69,14 & 85,83 & $2,70(1,53-4,75)$ & 0,001 \\
\hline Có & 30,86 & 14,17 & & \\
\hline
\end{tabular}

Hài lòng với cách quản lý, sắp xếp lịch học 


\begin{tabular}{ccccc}
\hline \multirow{2}{*}{ Nội dung } & \multicolumn{2}{c}{ Stress } & \multirow{2}{*}{ OR (95\%Cl) } & P \\
\cline { 2 - 3 } & Có (\%) & Không (\%) & & \\
\hline Không & 42,97 & 30,71 & $0,58(0,37-0,92)$ & 0,021 \\
\hline Có & 57,03 & 69,29 & & \\
\hline
\end{tabular}

\section{Chương trình học tập}

Phải học tập, làm việc cả ngày

\begin{tabular}{|c|c|c|c|c|}
\hline Không & 24,22 & 37,8 & \multirow{2}{*}{$1,90(1,20-3,00)$} & \multirow{2}{*}{0,006} \\
\hline Có & 75,78 & 62,2 & & \\
\hline \multicolumn{5}{|c|}{ Áp lực thi cử và điểm thi } \\
\hline Không & 10,55 & 24,41 & \multirow{2}{*}{$2,73(1,55-4,83)$} & \multirow{2}{*}{0,001} \\
\hline Có & 89,45 & 75,59 & & \\
\hline \multicolumn{5}{|c|}{ Cạnh tranh với các bạn cùng khóa } \\
\hline Không & 51,17 & 70,08 & \multirow{2}{*}{$2,23(1,42-3,51)$} & \multirow{2}{*}{0,000} \\
\hline Có & 48,83 & 29,92 & & \\
\hline \multicolumn{5}{|c|}{ Lo sợ thi trượt môn } \\
\hline Không & 26,17 & 40,94 & \multirow{2}{*}{$1,95(1,24-3,06)$} & \multirow{2}{*}{0,004} \\
\hline Có & 73,83 & 59,06 & & \\
\hline \multicolumn{5}{|c|}{ Chương trình học tập mới } \\
\hline Không & 45,31 & 62,99 & \multirow{2}{*}{$2,05(1,32-2,17)$} & \multirow{2}{*}{0,001} \\
\hline Có & 54,69 & 37,01 & & \\
\hline \multicolumn{5}{|c|}{ 5. Yếu tố học lâm sàng } \\
\hline \multicolumn{5}{|c|}{ Khó khăn trong việc tiếp cận, nhận sự hỗ trợ từ giảng viên } \\
\hline Không & 40,2 & 59,52 & \multirow{2}{*}{$2,18(1,05-4,55)$} & \multirow{2}{*}{0,036} \\
\hline Có & 59,8 & 40,48 & & \\
\hline
\end{tabular}

Khi tiến hành phân tích đơn biến, chúng tôi thấy nhóm yếu tố cá nhân có nhiều yếu tố liên quan đến stress nhất như: khó khăn tài chính, thiếu thời gian nghỉ ngơi, thiếu tự tin vào bản thân, sự kỳ vọng của bố mẹ... Tiếp theo là các yếu tố thuộc nhóm chương trình học tập: phải học cả ngày, áp lực thi cử, lo sợ thi trượt, cạnh tranh với bạn cùng khóa... (bảng 2). Phân tích hồi quy đa biến logistic chỉ còn 2 yếu tố liên quan có ý nghĩa thống kê là: sự thiếu tự tin vào bản thân $(O R=3,56 ; p=0,02)$ và sự kỳ vọng cao của bố mẹ $(O R=3,50 ; p=0,029)$ (bảng 3$)$. 


\section{Bảng 3. Mô hình hồi quy logistic tìm yếu tố liên quan đến tình trạng stress (phân tích đa biến)}

\begin{tabular}{lcccc}
\hline \multicolumn{1}{c}{ Yếu tố trong mô hình } & $\begin{array}{c}\text { Hệ số } \\
\text { hồi quy }\end{array}$ & $\begin{array}{c}\text { Sai số } \\
\text { chuẩn }\end{array}$ & $\mathbf{P}$ & OR $(\mathbf{9 5 \%} \mathbf{C l})$ \\
\hline Thiếu tự tin vào bản thân & 1,27 & 1,95 & 0,020 & $3,56(1,21-10,41)$ \\
\hline $\begin{array}{l}\text { Sự kỳ vọng của bố mẹ khiến cảm } \\
\text { thấy áp lực }\end{array}$ & 1,25 & 2,01 & 0,029 & $3,50(1,14-10,78)$ \\
\hline
\end{tabular}

\section{BÀN LUẬN}

\section{Về thực trạng stress}

Tỷ lệ sinh viên răng hàm mặt có stress trong nghiên cứu của chúng tôi là $66,84 \%$, tương đồng với kết quả nghiên cứu của một số tác giả trong nước như nghiên cứu của Phạm Thị Huyền Trang ở sinh viên Đại học $Y$ Hà Nội $(63,6 \%),{ }^{7}$ nghiên cứu của Nguyễn Việt Anh ở sinh viên trường Đại học Công nghệ - Đại học Quốc gia (68,0\%). ${ }^{9}$ Một số nghiên cứu của các tác giả trên thế giới cũng cho kết quả tỷ lệ stress ở sinh viên nha khoa rất cao như Mahawar $(86,7 \%) .^{10}$ Điều này cho thấy, tình trạng stress nói riêng và vấn đề sức khỏe tâm thần nói chung ở sinh viên răng hàm mặt cần được quan tâm.

Theo năm học, sinh viên năm thứ 6 và sinh viên năm thứ 5 có tỷ lệ stress cao nhất lần lượt là $73,97 \%$ và $71,79 \%$, điều này có lẽ bởi sinh viên các năm cuối có khối lượng học tập nhiều hơn, phải trực tiếp khám và điều trị cho bệnh nhân, áp lực thi cử tốt nghiệp... Kết quả này cũng tương tự nghiên cứu của Morse và Dravo, sinh viên 2 năm cuối có tỷ lệ stress cao nhất. ${ }^{11}$

Tỷ lệ stress ở sinh viên nữ là $68,91 \%$ cao hơn so với tỷ lệ ở sinh viên nam $63,45 \%$, tuy nhiên sự khác biệt này không có ý nghĩa thống kê. Theo một số nghiên cứu của các tác giả trên thế giới, tỷ lệ stress ở sinh viên nữ thường cao hơn so với sinh viên nam như nghiên cứu của I. Peker và cộng sự. ${ }^{5}$ Các nghiên cứu đưa ra lời giải thích sinh viên nữ thường nhạy cảm hơn về các vấn đề xảy ra xung quanh và cũng thường có những suy nghĩa hay cảm nhận quá mức so với bình thường. ${ }^{12}$

\section{Về các yếu tố liên quan}

Trong nghiên cứu của mình, chúng tôi sắp xếp các yếu tố liên quan đến stress ở sinh viên răng hàm mặt thành 5 nhóm gồm: điều kiện sống, yếu tố cá nhân, yếu tố trường học, chương trình học tập và yếu tố học lâm sàng. Nhóm yếu tố cá nhân có nhiều yếu tố liên quan đến stress ở sinh viên nhất, có thể kể đến như: sự thiếu tự tin vào bản thân, khó khăn về tài chính, tình trạng sức khỏe bản thân... Tiếp theo, nhóm yếu tố chương trình học tập cũng góp phần gây stress cho sinh viên như: phải học tập, làm việc cả ngày, áp lực thi cử, lo lắng thi trượt hoặc chương trình học tập mới... Ngoài ra các yếu tố như không khí học tập tại trường lớp, sự sẵn sàng hỗ trợ từ các giảng viên... cũng là yếu tố ảnh hưởng đến thực trạng stress ở sinh viên. Đối với sinh viên các năm cuối đã đi học lâm sàng, bên cạnh áp lực từ bệnh nhân thì những khó khăn trong việc tiếp cận sự hỗ trợ từ giảng viên khi thực hành lâm sàng cũng khiến các em lo lắng, căng thẳng.

Khi tiến hành phân tích hồi quy đa biến, hai yếu tố liên quan đến stress ở sinh viên răng hàm mặt là sự thiếu tự tin vào bản thân (OR $=3,56, p<0,05)$ và yếu tố sự kỳ vọng của bố mẹ $(O R=3,5, p<0,05)$. Kết quả nghiên cứu của chúng tôi có thể giải thích bởi đặc thù của 
sinh viên y nói chúng và sinh viên răng hàm mặt nói riêng phải trải qua quá trình học tập, rèn luyện căng thẳng để đáp ứng được các yêu cầu, tiêu chuẩn của chương trình đào tạo, đặc biệt trong các kỳ thi lý thuyết và lâm sàng. Do đó với những sinh viên không tự tin vào bản thân khi phải đối mặt với khó khăn, áp lực từ quá trình học tập, thi cử hoặc khi có kết quả thi không tốt sẽ rất dễ nảy sinh các trạng thái cảm xúc tiêu cực như mệt mỏi, chán chường...dẫn đến stress. Mặt khác, các bậc phụ huynh luôn có kỳ vọng cao đối với con của mình, đặc biệt với các bạn sinh viên răng hàm mặt đều luôn là học sinh giỏi, đạt kết quả học tập xuất sắc khi học phổ thông hay nói một cách khác bố mẹ đã quen với việc con mình luôn được điểm 9, điểm 10 trong mỗi kỳ thi. Do đó khi kết quả học ở trường $Y$ của các bạn sinh viên không cao, thậm chí thi trượt, không đạt kỳ vọng của phụ huynh thì chính bố mẹ sẽ cảm thấy thất vọng, không hài lòng. Khi đó bố mẹ có thể có những lời nói, hành động thậm chí là hình phạt gây áp lực lên các bạn sinh viên, dẫn tới làm tăng nguy cơ stress. Kết quả nghiên cứu của chúng tôi cũng phù hợp với một số nghiên cứu khác trên thế giới như theo nghiên cứu của Sreeramareddy và cộng sự, ${ }^{13}$ kỳ vọng cao của bố mẹ là một trong các nguyên nhân chính gây stress ở sinh viên ngành $Y$, nghiên cứu của Gomathi và cộng sự cho kết quả yếu tố kỳ vọng cao của bố mẹ là nguyên nhân gây stress phổ biến thứ 2 ở sinh viên $Y$ khoa. ${ }^{14}$

Các nghiên cứu trên thế giới cũng chỉ ra rằng các yếu tố thuộc nhóm chương trình học tập và yếu tố học lâm sàng là hai nhóm yếu tố gây stress cho sinh viên nha khoa nhiều nhất. ${ }^{15}$ Theo Kumar và cộng sự, các yếu tố hàng đầu gây stress cho sinh viên nha khoa là: áp lực thi cử và điểm số, phải học tập cả ngày, lo sợ thi trượt, lo lắng thất nghiệp khi ra trường, không khí học tập tạo ra bởi giảng viên ${ }^{16}$... Điều đó cho thấy, để giảm bớt tình trạng stress ở sinh viên nha khoa cần các giải pháp ở nhiều lĩnh vực khác nhau như cải tiến chương trình học tập, cách thi cử cũng như cần sự quan tâm hỗ trợ của giảng viên, đặc biệt khi sinh viên học lâm sàng..., về phía gia đình, bố mẹ cũng không nên đặt kỳ vọng quá cao, gây thêm áp lực cho các bạn sinh viên, đặc biệt khi kết quả học tập không được như mong muốn của bố mẹ.

\section{KÉT LUẬN}

Tỷ lệ stress ở sinh viên Răng hàm mặt Trường Đại học $Y$ Hà Nội là 66,84\%. Theo giới tính, tỷ lệ stress ở nam là $63,45 \%$, ở nư là $68,91 \%$; theo năm học tỷ lệ stress cao nhất ở sinh viên năm thứ $6(73,97 \%)$, thấp nhất ở sinh viên năm thứ 4 với $60,66 \%$. Stress ở sinh viên nha khoa có liên quan đến một số yếu tố, trong đó có hai yếu tố ảnh hưởng nhiều nhất là sự thiếu tự tin vào bản thân và áp lực từ sự kỳ vọng của bố mẹ. Nghiên cứu của chúng tôi mới chỉ tiến hành trên sinh viên răng hàm mặt Trường Đại học Y Hà Nội và lấy số liệu tại 1 thời điểm nghiên cứu, do vậy nên có các nghiên cứu tiếp theo ở các trường đại học khác có hệ đào tạo bác sỹ răng hàm mặt và có thể lấy số liệu ở những thời điểm khác nhau trong năm học, để so sánh tỷ lệ stress ở sinh viên giữa các trường, ở các thời điểm khác nhau và xác định thêm các yếu tố nguy cơ ảnh hưởng đến stress ở sinh viên răng hàm mặt.

\section{Lời cảm ơn}

Nhóm nghiên cứu xin bày tỏ lời cảm ơn tới các sinh viên đã tham gia vào nghiên cứu và Viện Đào tạo Răng hàm mặt - Trường Đại học Y Hà Nội đã hỗ trợ để thực hiện nghiên cứu này.

\section{TÀI LIẸU THAM KHẢO}

1. Tosevski DL, Milovancevic MP, Gajic SD. Personality and psychopathology of university students: Current Opinion in Psychiatry. 2010;23(1):48-52. doi:10.1097/ YCO.0b013e328333d625 
2. Birks Y, McKendree J, Watt I. Emotional intelligence and perceived stress in healthcare students: a multi-institutional, multi-professional survey. BMC Medical Education. 2009;9(1):61. doi:10.1186/1472-6920-9-61

3. Piazza-Waggoner CA, Cohen LL, Kohli K, Taylor BK. Stress management for dental students performing their first pediatric restorative procedure. J Dent Educ. 2003;67(5):542-548.

4. Sanders AE, Lushington K. Sources of stress for Australian dental students. J Dent Educ. 1999;63(9):688-697.

5. Peker İ. The evaluation of perceived sources of stress and stress levels among Turkish dental students. International Dental Journal. Published online April 1, 2009:103-111. doi:10.1922/IDJ_2010Peker09

6. Tangade PS, Mathur A, Gupta R, Chaudhary S. Assessment of Stress Level among Dental School Students: An Indian Outlook. Dent Res J (Isfahan). 2011;8(2):95-101.

7. Phạm Thị Huyền Trang. Thực trạng stress ở sinh viên đại học Y Hà Nội năm 2013. Published online 2013.

8. Trần Đức Thạch, Trần Tuấn, Fisher J. Validation of the depression anxiety stress scales (DASS) 21 as a screening instrument for depression and anxiety in a rural community-based cohort of northern Vietnamese women. BMC Psychiatry. 2013;13(1):24. doi:10.1186/1471244X-13-24

9. Nguyễn Việt Anh. Thực trạng và các yếu tố liên quan đến stress của sinh viên năm thứ 3 Trường đại học công nghệ, Đại học Quốc gia
Hà Nội năm 2015. Published online 2015.

10. Mahawar P, Phadnis S, Ghosh G, Kataria O, Dixit S. Psychological Morbidity in Students of Medical College and Science and Art College Students - A Comparative Study. :3.

11. Morse Z, Dravo U. Stress levels of dental students at the Fiji School of Medicine. Eur J Dent Educ. 2007;11(2):99-103. doi:10.1111/ j.1600-0579.2007.00435.x

12. Deshpande A, Chari S. Perceived Sources of Stress and Coping Strategies in Dental Students and Interns. Journal of Psychology. 2014;5(2):133-141. doi:10.1080/09764224.201 4.11885513

13. Sreeramareddy CT, Shankar PR, Binu V, Mukhopadhyay C, Ray B, Menezes RG. Psychological morbidity, sources of stress and coping strategies among undergraduate medical students of Nepal. BMC Med Educ. 2007;7(1):26. doi:10.1186/1472-6920-7-26

14. Gomathi KG, Ahmed S, Sreedharan J. Causes of Stress and Coping Strategies Adopted by Undergraduate Health Professions Students in a University in the United Arab Emirates. Sultan Qaboos Univ Med J. 2013;13(3):437-441.

15. Elani HW, Kumar RA, Bedos C. A Systematic Review of Stress in Dental Students. Journal of Dental Education. 2014;78(2):17.

16. Kumar S, Dagli RJ, Mathur A, Jain M, Prabu D, Kulkarni S. Perceived sources of stress amongst Indian dental students. European Journal of Dental Education. 2009;13(1):3945. doi:10.1111/j.1600-0579.2008.00535.x 


\section{Summary}

\section{PREVALENCE OF STRESS AND SOME OF ITS RELATED-FACTORS AMONG DENTAL STUDENTS OF HANOI MEDICAL UNIVERSITY}

Dental students have high risk of stress. Stress can cause negative affect on the mental health, study ability and life quality of dental students. In Vietnam, study about stress among dental student was not yet performed so we did this study to investigate the prevalence of stress and its related factors among dental students in Hanoi Medical University. This was a cross-sectional descriptive study comprised of 383 dental students in Hanoi medical university. 256 out of 383 students suffered stress $(66.84 \%)$. The prevalence of stress in male was $63.45 \%$ and in female was $68.91 \%$. The ratio of stress level of moderate, severe and very severe were $34.46 \%, 8.88 \%$ and $6.27 \%$ respectively. 6 th-year-students reach the highest stress ratio (73.97\%). Some related-factors included lack of selfbelief and parental high expectation. The stress prevalence of dental students was very high and its related factor included: lack of self-belief and parental high expectation.

Keyword: stress, dental students, lack of self-belief, parental high expectation. 